\title{
Characterization of Pseudomonas aeruginosa MCC 3198 and its Potential for Growth Promotion of Seedlings of the Medicinal Plant Celosia cristata L.
}

\author{
Sunanda Dutta, Avishek Sarkar and Sikha Dutta*
}

Applied Mycology and Molecular Plant Pathology Laboratory, CAS Department of Botany, The University of Burdwan, Burdwan-713104, West Bengal, India

*Corresponding author

\begin{tabular}{l} 
K e y w or d s \\
$\begin{array}{l}\text { Celosia cristata, } \\
\text { PGPR, } \\
\text { Pseudomonas } \\
\text { aeruginosa }\end{array}$ \\
Article Info \\
$\begin{array}{l}\text { Accepted: } \\
10 \text { March } 2019 \\
\text { Available Online: } \\
10 \text { April } 2019\end{array}$ \\
\hline
\end{tabular}

Keywords

Celosia cristata PGPR,

Pseudomonas aeruginosa

Article Info

Accepted:

Available Online:

10 April 2019

\section{A B S T R A C T}

Conservative methods of harvest propagation to develop expansion and yield of vegetation underneath in diverse ecological threats are lengthy and not triumphant in many cases. Use of expensive injurious agrochemicals and pesticides causes stern danger to environment and renders growth of challenging pathogens. At present time, more and more attention has been made towards cost-effective and environment-friendly alternatives to improve natural wealth and assist plant development. Beneficial bacteria, particularly in the rhizosphere of plants, are deliberated and established to exert growth-promoting activities. These important rhizobacteria consist of the symbiotic Rhizobium species, few specific actinomycetes, mycorrhizal fungi and some free-living bacteria. Plant growth promoting rhizobacteria (PGPR) are a cluster of favorable bacteria which have the prospective for improving plant growth, development and yield. Research works on the effect of PGPR on medicinal plants are very limited. Accordingly, the present communication is dealt with the characterization of PGPR bacteria isolated from the rhizosphere of little explored medicinal herb, Celosia cristata L. The bacterium was identified as Pseudomonas aeruginosa (MCC 3198). Seed germination, seedling vigor, root length, shoot length, leaf count, dry and fresh weight, chlorophyll content and some defense enzymes of the plant $C$. cristata have significantly been improved as a result of application of this bacteria.

\section{Introduction}

Plant growth-promoting rhizobacteria (PGPRs) is a specific group of soil bacteria that aggressively colonize the rhizosphere and rhizoplane, and substantially improve plant growth and productivity. PGPR work as plant growth promoters and biological control agents via direct or indirect mechanisms.
Direct mechanisms by PGPRs include the provision of bioavailable phosphorus and nitrogen for plant uptake, sequestration of iron by siderophores, production of plant hormones like, auxins, cytokinins, and gibberellins, and lowering ethylene levels inside plants using ACC deaminase that accumulate in plants subjected to biotic and abiotic stresses (Glick, 1995; Glick et 
al., 1999; Mayak et al., 2004). The indirect mechanisms include the production of antibiotics, reducing iron availability for phytopathogens in the rhizosphere, enzymatic lysis of fungal cell wall and insect-gut membrane secreting chitinase enzyme for the hydrolysis of chitin layer of the eggshell of nematodes, competition with detrimental microorganisms for sites on plant roots, and induction of systemic resistance in plants against various pathogens and pests (Ramamoorthy et al., 2001). Bacterial strains showing PGPR activity have been reported for diverse bacterial taxa including Agrobacterium, Arthrobacter, Azotobacter, Azospirillum, Bacillus, Burkholderia, Caulobacter, Chromobacterium, Erwinia, Flavobacterium, Micrococcus, Pseudomonas, and Serratia (Gray and Smith, 2005).

To date, PGPRs have been shown to promote the growth of cereals, ornamentals, vegetables, and food crops (Vessey, 2003; Lugtenberg and Kamilova, 2009; Mishra et al., 2010). However, a limited number of studies have been undertaken regarding the interactions between PGPRs and medicinal or aromatic plants. This communication, therefore, aims to bring in-verified or putative mechanisms by which PGPRs promote seed germination, intensification, nutrient acquisition, and defense response in aromatic and medicinal plants.

\section{Materials and Methods}

\section{Isolation and screening of Plant Growth Promoting Rhizobacteria (PGPR)}

The plant Celosia cristata L. were collected from the garden of the department of Botany, The University of Burdwan, Burdwan (23.2565951, 87.8434078) to isolate PGPR. The plant was maintained with proper care in the garden. The Rhizobacteria were isolated from the root adhering soil of $C$. cristata $\mathrm{L}$. by serial dilution technique and plated on Pikovskaya's agar medium (Pikovskaya, 1948) [Yeast extract-0.50 g; Dextrose-10.00 g; Calcium phosphate-5.00 g; Ammonium phosphate-0.50 g; Potassium chloride-0.20 g; Magnesium sulphate-0.10 g; Manganese sulphate-0.0001 g; Ferrous sulphate-0.0001 g; Agar-15.00 g; Water - 1000 ml; pH - 6.5].

Scattered colonies appeared in the plate after 3 days of incubation at $30 \pm 1^{\circ} \mathrm{C}$ were observed and one colony (SD/B) was selected as it exhibited the highest diameter of halo zone around the colony. Pure cultured of the isolate $\mathrm{SD} / \mathrm{B}$ was then made by dilution streak method and maintained in the same medium with a sub-culturing period of 15 days and used for further studies.

\section{Identification and phylogeny of the selected} isolate $\mathrm{SD} / \mathrm{B}$

\section{Phenotype based identification}

The selected phenotypic characterization such as cell size, colony morphology, gram staining behaviour and oxygen requirement was studied following the methods of Benson (2002).

\section{Molecular identification}

The molecular identification of the selected $\mathrm{SD} / \mathrm{B}$ isolate was done by $16 \mathrm{~S}$ rDNA sequencing. For this, the genomic DNA was isolated by the standard chloroform extraction method (Sambrook et. al., 1989) followed by PCR amplification of $16 \mathrm{~S}$ rDNA. The universal primers 5'-GAG TTT GAT CCT GGC TCA G-3' was used as forward primer and 5'-AGA AAG GAG GTG ATC CAG CC-3' was used as reverse primer. The amplified PCR product was purified by PEG$\mathrm{NaCl}$ precipitation and sequenced in an automated DNA Sequencer (Applied Biosystems Inc., Foster city, CA). Sequence 
assembly was carried out by the Lasergene package software and identified by EZ-Taxon search considering the $16 \mathrm{~S}$ rDNA sequence of $\mathrm{SD} / \mathrm{B}$ as query sequence. The $16 \mathrm{~S}$ rDNA sequence was deposited to NCBI to obtain sequence accession number.

\section{Construction of phylogenetic tree}

The phylogenetic tree of the selected isolate $\mathrm{SD} / \mathrm{B}$ was built using the $16 \mathrm{~S}$ rDNA sequences of valid strains obtained from EZtaxon, National Centre for Biotechnology Identification (NCBI) and Rhibosomal Database Project (RDP) sequence database searching. MEGA7 Software (Kumar et. al., 2016) was used to construct the phylogenetic tree.

Characterization of plant growth promoting traits of $\mathrm{SD} / \mathrm{B}$ strain

\section{Phosphate solubilization}

The phosphate solubilizing ability of the bacteria SD/B was detected using Pikovskaya's agar plates. The phosphate solubilizing ability was observed by using dicalcium phosphate (DCP), tri-calcium phosphate (TCP) and zinc phosphate (ZP) separately in Pikovskaya's agar medium for detecting a clear zone around the colonies.

Quantitative estimation of phosphates solubilization was determined following ammonium molybdate method (Yoon SJ et al., 1996).

\section{Test for nitrogen fixation}

The ability to fix atmospheric nitrogen was tested by inoculating the isolate SD/B in the Asbay's Mannitol Agar media without ready source of nitrogen i.e. Ammonium sulphate and they are allowed to incubate at $30 \pm 2^{\circ} \mathrm{C}$ temperature for 3 days. Occurrence of bacterial growth indicates its ability to fix atmospheric nitrogen.

\section{Iindole-3-acetic acid (IAA) production}

Qualitative and quantitative Iindole-3-acetic acid (IAA) Production by the bacterial strain (SD/B) was done by the method of Brick et.al. (1991).

\section{Hydrocyanic acid (HCN) production}

HCN production was determined by the picrate assay (Lorck, 1948).

\section{Ammonia production}

The ammonia production ability of the isolate was tested using the method of Cappuccino and Sherman (1992).

\section{Assay of siderophore production}

The Fe(III) specific ligand as deterrent of soil borne phytopathogens was assayed following the method of Schwyn and Neilands (1987).

\section{Protease activity}

Protease activity was determined following Chaiharn (2008) [Composition of protein precipitating reagent was- Mercuric chloride $3 \mathrm{~g}$, Concentrated $\mathrm{HCl}-4 \mathrm{ml}$, Distilled water $20 \mathrm{ml}]$

\section{In vitro plant growth promotion experiment}

Mature $C$. cristata L. seeds were surface sterilized with $0.1 \% \mathrm{HgCl}_{2}$ for 3 min followed by successive washing with sterile distilled water and then the water was decanted. The seeds were kept for 10 minutes in the broth culture of bacteria on the log phase containing $4.9 \times 10^{6}$ colony forming unit $(\mathrm{CFU}) / \mathrm{ml}$. For germination, seeds were then placed in 
sterilized Petri plates containing moist filter paper at $25 \pm 2{ }^{\circ} \mathrm{C}$ for 3 days in the dark and then transferred to a growth room for 11 days $\left[28 \pm 2{ }^{\circ} \mathrm{C}\right.$ temperature, $\mathrm{RH} 70-80 \%$, illumination $270 \mathrm{mE} \mathrm{m}^{-2} \mathrm{~s}^{-1}$ (for $12 \mathrm{~h}$ )]. Seeds treated with sterilized medium without bacterial culture were considered as control. After germination the seedlings were examined for following parameters like-

Study of the effect of SD/B on seed germination and morphological parameters of the seedlings

After completion of 14 days of growth, various growth parameters like, Germination percentage, root length, shoot length and seedling vigor index were recorded.

\section{Germination percentage}

The germination percentage of both the control and PGPR treated sets were calculated by using the following formula

Germination Percentage $=\frac{\text { Total no. of seed germinated }}{\text { total no of seeds in all replicates }} X 100$

\section{Seedling vigor index}

Seedling vigor index (SVI) was calculated according to Abdul-Baki and Anderson (1973) by using following equation-

$\mathrm{SVI}=\mathrm{SDW}($ or $\mathrm{SL}) \times \mathrm{GP}$

Where, GP- germination percentages, SDWseedling dry weight and SL-seedling length (shoot length + root length) in $\mathrm{mm}$, respectively.

\section{Estimation of total chlorophyll}

Estimation of total chlorophyll of seedlings was done following Acetone extraction method of Arnon (1949).
Study of the effect of SD/B on biochemical parameters of seedlings

Estimation of proline content: Proline content of control and PGPR treated seedlings was done following the method of Bates et al., (1973).

Enzyme extraction from seedlings: $1 \mathrm{~g}$ tissue of freshly grown seedling from each set (control as well as PGPR treated sets) were taken and homogenized in pri-chilled mortar pestle containing $10 \mathrm{ml}$ of ice cold $50 \mathrm{mM}$ Tris - Acetate buffer of pH-6.0. Then the homogenate were centrifuged at $14000 \mathrm{rpm}$ in $4^{\circ} \mathrm{C}$ temperature for 20 munities. The supernatant were then filtered through Sephadex G-25 column, and was ready to estimate the activities of defense enzymes like, SOD, Catalase, Polyphenol oxidase and Peroxidase.

\section{Estimation of SOD activity of seedlings}

It was measured using the method of Beauchamp and Fridovich, (1973) and expressed as Unit/g.fw.

\section{Estimation of catalase activity of seedlings}

It was measured using the method of Aebi, (1984) and expressed as EU/min/g fresh weight.

Estimation of peroxidase activity of seedling

It was done using the method of Addy and Goodman, (1972) and expressed as Unit/ml.

Estimation of ascorbate oxidase activity of seedling

It was done using the method of Vines and Oberbacher (1965) and expressed as Units/ml enzyme. 


\section{Results and Discussion}

The plant growth promoting rhizobacteria possess important PGP traits that enhance plant growth and maintain plant health essential for sustainable agriculture. Moreover, it also possesses the ability to improve the growth of medicinal plant correspondingly increase secondary metabolite production. Considering this PGPR was isolated from Celosia cristata L, followed by its characterization and testing for the plant growth promotion ability.

\section{Isolation and screening of Plant Growth Promoting Rhizobacteria (PGPR)}

The Rhizobacteria were isolated from the root adhearing soil of $C$. cristata L. by serial dilution technique and plated on Pikovskaya's agar medium.The isolated bacteria were selected based on the diameter of the halo zone which indicated their phosphate solubilizing ability and accordingly characterised for identification.

Identification and phylogeny of the selected isolate $\mathrm{SD} / \mathrm{B}$

\section{Phenotype based identification}

The phenotypic characterization of the selected SD/B was made as per standard method which are given in Table 1 and Figure 1a,b.

\section{Molecular identification}

Based on 16S rDNA sequence homology, the strain $\mathrm{SD} / \mathrm{B}$ showed $100 \%$ pair wise similarity with Pseudomonas aeruginosa [JCM 10591] (Table 1-a). The phylogenetic tree revealed that the SD/B strain formed the cluster with Pseudomonas aeruginosa JCM 5962(T). The $16 \mathrm{~S}$ rDNA of SD/B strain is given below in FASTA format and strain accession number of this strain obtained from MCC is MCC3198.

Information about other close homologs for the microbes can be obtained from the Alignment View table (Table 1a).

FASTA Sequence of SD/B (1421 bp)

AGAGTTTGATCATGGCTCAGATTGAAC GCTGGCGGCAGGCCTAACACATGCAA GTCGAGCGGATGAAGGGAGCTTGCTC CTGGATTCAGCGGCGGACGGGTGAGT AATGCCTAGGAATCTGCCTGGTAGTGG GGGATAACGTCCGGAAACGGGCGCTA ATACCGCATACGTCCTGAGGGAGAAA GTGGGGGATCTTCGGACCTCACGCTAT CAGATGAGCCTAGGTCGGATTAGCTAG TTGGTGGGGTAAAGGCCTACCAAGGC GACGATCCGTAACTGGTCTGAGAGGAT GATCAGTCACACTGGAACTGAGACAC GGTCCAGACTCCTACGGGAGGCAGCA GTGGGGAATATTGGACAATGGGCGAA AGCCTGATCCAGCCATGCCGCGTGTGT GAAGAAGGTCTTCGGATTGTAAAGCA CTTTAAGTTGGGAGGAAGGGCAGTAA GTTAATACCTTGCTGTTTTGACGTTACC AACAGAATAAGCACCGGCTAACTTCGT GCCAGCAGCCGCGGTAATACGAAGGG TGCAAGCGTTAATCGGAATTACTGGGC GTAAAGCGCGCGTAGGTGGTTCAGCA AGTTGGATGTGAAATCCCCGGGCTCAA CCTGGGAACTGCATCCAAAACTACTGA GCTAGAGTACGGTAGAGGGTGGTGGA ATTTCCTGTGTAGCGGTGAAATGCGTA GATATAGGAAGGAACACCAGTGGCGA AGGCGACCACCTGGACTGATACTGAC ACTGAGGTGCGAAAGCGTGGGGAGCA AACAGGATTAGATACCCTGGTAGTCCA CGCCGTAAACGATGTCGACTAGCCGTT GGGATCCTTGAGATCTTAGTGGCGCAG CTAACGCGATAAGTCGACCGCCTGGG GAGTACGGCCGCAAGGTTAAAACTCA AATGAATTGACGGGGGCCCGCACAAG CGGTGGAGCATGTGGTTTAATTCGAAG CAACGCGAAGAACCTTACCTGGCCTTG 
ACATGCTGAGAACTTTCCAGAGATGGA TTGGTGCCTTCGGGAACTCAGACACAG GTGCTGCATGGCTGTCGTCAGCTCGTG TCGTGAGATGTTGGGTTAAGTCCCGTA ACGAGCGCAACCCTTGTCCTTAGTTAC CAGCACCTCGGGTGGGCACTCTAAGG AGACTGCCGGTGACAAACCGGAGGAA GGTGGGGATGACGTCAAGTCATCATG GCCCTTACGGCCAGGGCTACACACGTG CTACAATGGTCGGTACAAAGGGTTGCC AAGCCGCGAGGTGGAGCTAATCCCAT AAAACCGATCGTAGTCCGGATCGCAGT CTGCAACTCGACTGCGTGAAGTCGGAA TCGCTAGTAATCGTGAATCAGAATGTC ACGGTGAATACGTTCCCGGGCCTTGTA CACACCGCCCGTCACACCATGGGAGTG GGTTGCTCCAGAA

\section{Construction of phylogenetic tree}

Based on 16S rDNA sequences of valid strains obtained from EZ-taxon, National Centre for Biotechnology Identification (NCBI) and Rhibosomal Database Project (RDP) sequence database a phylogenetic tree of SD/B strain was made (Fig. 2). The evolutionary history was inferred using the Maximum Parsimony method. Tree \#1 out of 2 most parsimonious trees (length $=479$ ) is shown. The consistency index is (0.697674), the retention index is $(0.666667)$, and the composite index is $0.648573(0.465116)$ for all sites and parsimony-informative sites (in parentheses). The percentage of replicate trees in which the associated taxa clustered together in the bootstrap test (100 replicates) are shown next to the branches (Felsenstein, 1985). The MP tree was obtained using the Sub-tree-Pruning-Regrafting (SPR) algorithm (Nei and Kumar, 2000) with search level 1 in which the initial trees were obtained by the random addition of sequences (10 replicates). The analysis involved 8 nucleotide sequences. All positions containing gaps and missing data were eliminated. There were a total of 1329 positions in the final dataset.
Evolutionary analyses were conducted in MEGA7 (Kumar et al., 2016).

\section{Characterization of plant growth promoting traits of SD/B strain}

The plant growth promoting (PGP) traits are essential for plant growth promotion. Following PGP traits of the selected SD/B strain are detected and these are given in Table 2 and 3 (Fig. 3; Plate a, b, c, e, f).

This table shows the results of the quantitative tests done for the isolated PGPR where it has been found that the PGPR of our interest solubilize $24 \mathrm{ppm}$ of phosphate per $\mathrm{ml}$; produce $35 \mathrm{ppm}$ of IAA $/ \mathrm{ml}$; The OD values of $\mathrm{P}_{4}$ and IAA has been put to respective standard curve to determine the concentration.

Study of the effect of SD/B on seed germination, morphological and biochemical parameters of the seedlings

The effect of the selected SD/B isolate on Seed Germination, Morphological and Biochemical Parameters of the Seedlingswas made as per standard method which are given in Table 4 (Fig. 3; Plate g, h, i, j, k, 1, m).

Table 4 shows that the PGPR treatment displayed higher seedling vigor index than control or untreated seedlings which were 24.699 and 5.64 respectively. The chlorophyll-a, b, total chlorophyll content of treated plants have been recorded to be 125 $\mathrm{mg} / \mathrm{ml}, 325 \mathrm{mg} / \mathrm{ml}, 450 \mathrm{mg} / \mathrm{ml}$ respectively which were also appeared to be higher than control. In cases of the stress, Proline and defense enzyme like, Peroxidase activity of the non-treated plants were found to be 0.228 $\mu \mathrm{mol} \mathrm{g}{ }^{-1} \mathrm{FW}$ and $94 \mathrm{Unit} / \mathrm{ml} / \mathrm{min}$ respectively in contrast to $0.138 \mu \mathrm{mol} \mathrm{g} \mathrm{g}^{-1} \mathrm{FW}$ and 243 Unit $/ \mathrm{ml} / \mathrm{min}$ of the treated seedlings. Correspondingly, the defense enzymes like, Catalase $(0.185 \mathrm{EU} / \mathrm{min} / \mathrm{g}$ fresh weight), 
Superoxide Dismutase (SOD) (231 Unit/g fresh weight $/ \mathrm{min}$ ) and Ascorbate oxidase (0.265 units $/ \mathrm{min} / \mathrm{g} \mathrm{fw})$ were higher in treated seedlings than that of control ones $(0.120$ $\mathrm{EU} / \mathrm{min} / \mathrm{g}$ fresh weight; $188 \mathrm{Unit} / \mathrm{min} / \mathrm{g}$.fw, 0.250 units $/ \mathrm{min} / \mathrm{g}$ fw of the enzymes like, Catalase, SOD and Ascorbate oxidase respectively).

The rhizosphere represent one of the most intricate ecosystem on Earth by means of about every root on the world anticipated to have a chemically, physically, and biologically exclusive rhizosphere. Regardless of its inherent complication, consideration of the rhizosphere is vital if we are to resolve some of the world's mainly imminent ecological crises, like, sustainable foodstuff, yarn and energy fabrication and upliftment of active secondary metabolite production of medicinally important herbs.

This study gave us an insight into the bacterial community present in the rhizospheric soil of a medicinally important plant $C$. cristata $\mathrm{L}$. from where we have isolated a bacteria exhibiting the highest diameter of halo zone around the colony on Pikovskaya's agar medium (Pikovskaya, 1948) and designated it as SD/B. In our study we found that the isolated bacterial strain SD/B to be Pseudomonas aeruginosa, which is a gram negative, aerobic bacteria of 0.8 to $1.2 \mu \mathrm{M}$ in length. Pseudomonas aeruginosa JCM 5962(T) was first isolated from soil and described by Schroeter, 1872; Migula, 1900; though, the plant growth promoting activity of this bacteria has not been reported earlier.

Table.1 Phenotypic characteristics of the isolate SD/B

\begin{tabular}{|l|c|}
\hline \multicolumn{1}{|c|}{ Parameters } & Result \\
\hline Colony Morphology & Round, Raised \\
\hline Cell Size & $0.8-1.2 \mu \mathrm{M}$ \\
\hline Shape & Small, Rod shaped \\
\hline Gram Staining Behavior & Gram-negative \\
\hline Oxygen Requirement & Aerobic \\
\hline
\end{tabular}

Table.1a Significant alignments produced by the sequence

\begin{tabular}{|c|l|l|l|l|c|}
\hline Rank & \multicolumn{1}{|c|}{ Name } & \multicolumn{1}{|c|}{ Strain } & \multicolumn{1}{|c|}{ Authors } & \multicolumn{1}{|c|}{ Accession } & Pair wise Similarity(\%) \\
\hline $\mathbf{1}$ & Pseudomonas aeruginosa & $\begin{array}{l}\text { JCM } \\
\text { 5962(T) }\end{array}$ & $\begin{array}{l}\text { (Schroeter 1872) } \\
\text { Migula 1900 }\end{array}$ & $\begin{array}{l}\text { BAMA01000 } \\
\text { 316 }\end{array}$ & 100 \\
\hline $\mathbf{2}$ & Pseudomonas aeruginosa & paerg010 & Noll B,N.2018 & LR130536.1 & 100 \\
\hline $\mathbf{3}$ & Pseudomonas aeruginosa & paerg011 & Noll B,N.2018 & LR130535 & 100 \\
\hline $\mathbf{4}$ & Pseudomonas aeruginosa & paerg012 & Noll B,N.2018 & LR130537.1 & 100 \\
\hline $\mathbf{5}$ & Pseudomonas aeruginosa & paerg005 & Noll B,N.2018 & LR130534.1 & 100 \\
\hline $\mathbf{6}$ & Pseudomonas aeruginosa & paerg009 & Noll B,N.2018 & LR130533.1 & 100 \\
\hline $\mathbf{7}$ & Pseudomonas aeruginosa & paerg004 & Noll B,N.2018 & LR130531.1 & 100 \\
\hline $\mathbf{8}$ & Pseudomonas aeruginosa & paerg003 & Noll B,N.2018 & LR130530.1 & 100 \\
\hline $\mathbf{9}$ & Pseudomonas aeruginosa & paerg000 & Noll B,N.2018 & LR130528.1 & 100 \\
\hline $\mathbf{1 0}$ & Pseudomonas aeruginosa & paerg002 & Noll B,N.2018 & LR130527.1 & 100 \\
\hline
\end{tabular}


Table.2 Qualitative estimation of PGPR traits

\begin{tabular}{|l|c|}
\hline \multicolumn{1}{|c|}{ Characters } & Bacterial strains \\
\cline { 2 - 2 } & SD/B \\
\hline Phosphate solublization & ++++ \\
\hline $\mathbf{N}_{2}$ fixation & ++++ \\
\hline IAA production & +++ \\
\hline $\mathrm{NH}_{3}$ production & +++ \\
\hline HCN production & ++++ \\
\hline Protease activity & ++++ \\
\hline Siderophore activity & - \\
\hline
\end{tabular}

* (Data's are mean value of three replicates) [Values are mean $\pm \mathrm{SD} ;(\mathrm{n}=5) * * \mathrm{P} \& \mathrm{lt} ; 0.05$, significant, compared to control]

The above table shows the results of the qualitative tests done for the isolated PGPR. ' + ' sign represented the test is positive, more '+'signs means more positive. '- 'sign indicated the test is negative.

Table.3 Quantitative Estimation of PGPR Traits

\begin{tabular}{|l|c|}
\hline \multicolumn{1}{|c|}{ Characters } & Bacterial strains \\
\cline { 2 - 2 } & SD/B \pm SD \\
\hline Phosphate solublization & $24 \pm 0.026 \mathrm{ppm} / \mathrm{ml}$ \\
\hline IAA production & $35 \pm 0.016 \mathrm{ppm} / \mathrm{ml}$ \\
\hline
\end{tabular}

* (Data's are mean value of three replicates) [Values are mean $\pm \mathrm{SD} ;(\mathrm{n}=5) * * \mathrm{P} \& \mathrm{lt} ; 0.05$, significant, compared to control]

This table shows the results of the quantitative tests done for the isolated PGPR where it has been found that the PGPR of our interest solubilize $24 \mathrm{ppm}$ of phosphate per ml; produce $35 \mathrm{ppm}$ of IAA/ml; The OD values of $\mathrm{P}_{4}$ and IAA has been put to respective standard curve to determine the concentration.

Table.4 Effect on seed germination, seedling growth and defense

\begin{tabular}{|c|c|c|}
\hline \multirow[t]{2}{*}{ Estimation } & \multicolumn{2}{|c|}{ Treatment } \\
\hline & Control \pm SD & Treated with $\mathrm{PGPR} \pm \mathrm{SD}$ \\
\hline Germination Percentage & $60 \pm 0.25 \%$ & $78.66 \pm 0.34 \%$ \\
\hline Root Length & $1.0 \pm 0.4 \mathrm{~cm}$ & $2.0 \pm 0.19 \mathrm{~cm}$ \\
\hline Shoot Length & $2.4 \pm 0.03 \mathrm{~cm}$ & $4.0 \pm 0.09 \mathrm{~cm}$ \\
\hline Root Dry-weight & $5 \pm 0.036 \mathrm{mg}$ & $37 \pm 0.041 \mathrm{mg}$ \\
\hline Shoot Dry-weight & $89 \pm 0.027 \mathrm{mg}$ & $211 \pm 0.059 \mathrm{mg}$ \\
\hline Seedling vigor Index & 5.64 & 24.699 \\
\hline Chlorophyll - a & $20 \pm 0.01 \mathrm{mg} / \mathrm{ml}$ & $125 \pm 0.07 \mathrm{mg} / \mathrm{ml}$ \\
\hline Chlorophyll - b & $180 \pm 0.07 \mathrm{mg} / \mathrm{ml}$ & $325 \pm 0.03 \mathrm{mg} / \mathrm{ml}$ \\
\hline Total Chlorophyll & $200 \pm 0.08 \mathrm{mg} / \mathrm{ml}$ & $450 \pm 0.1 \mathrm{mg} / \mathrm{ml}$ \\
\hline Proline content & $0.228 \pm 0.007 \mu \mathrm{mol} \mathrm{g}^{-1} \mathrm{FW}$ & $0.138 \pm 0.004 \mu \mathrm{mol} \mathrm{g}^{-1} \mathrm{FW}$ \\
\hline Catalase activity & $0.120 \pm 0.006 \mathrm{EU} / \mathrm{min} / \mathrm{g}$ fresh weight & $0.185 \pm 0.005 \mathrm{EU} / \mathrm{min} / \mathrm{g}$ fresh weight \\
\hline Superoxide Dismutase activity & $188 \pm 0.2$ Unit/g.fw/min & $231 \pm 0.7$ Unit/g.fw/min \\
\hline Peroxidase activity & $94 \pm 0.74 \mathrm{Unit} / \mathrm{ml} / \mathrm{min}$ & $243 \pm 0.36 \mathrm{Unit} / \mathrm{ml} / \mathrm{min}$ \\
\hline Ascorbate oxidase activity & $0.250 \pm 0.001$ units $/ \mathrm{min} / \mathrm{ml}$ enzyme & $0.265 \pm 0.005$ units $/ \mathrm{min} / \mathrm{ml}$ enzyme \\
\hline
\end{tabular}

* (Data's are mean value of three replicates) [Values are mean $\pm \mathrm{SD} ;(\mathrm{n}=5) * * \mathrm{P} \& 1 \mathrm{lt} ; 0.05$, significant, compared to control] 
Fig.1 Microscopic view of bacterial slide (a) and SEM view of SD/B (b)

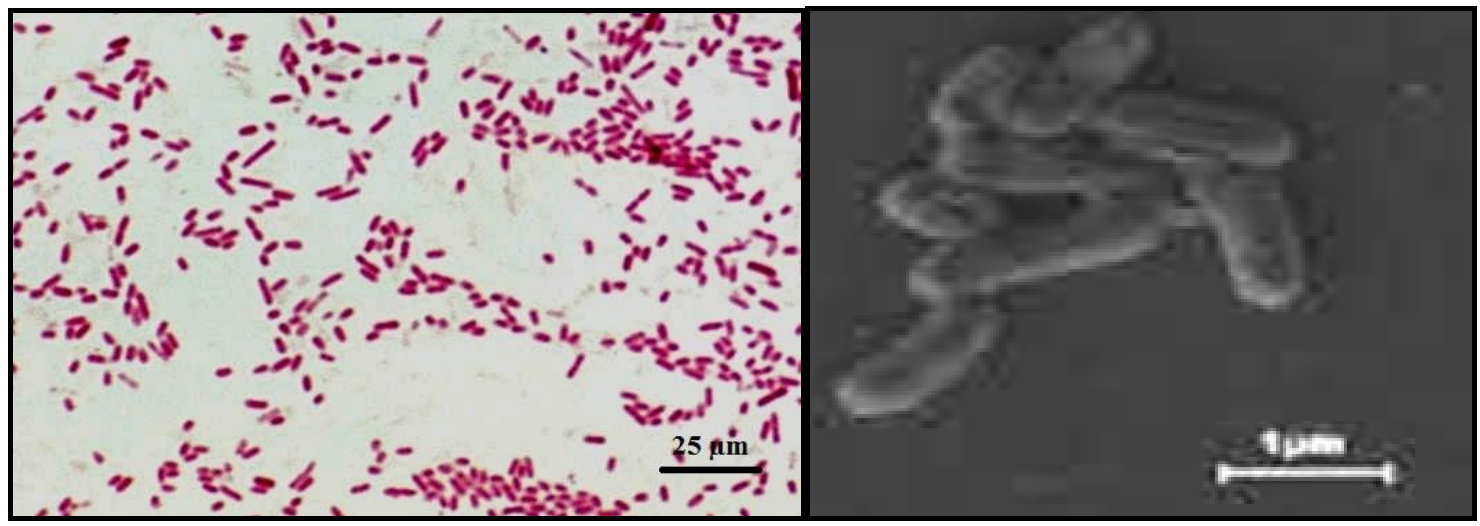

a.

b.

Fig.2 Phylogenetic tree of SD/B strain with other strains of homologous sequences

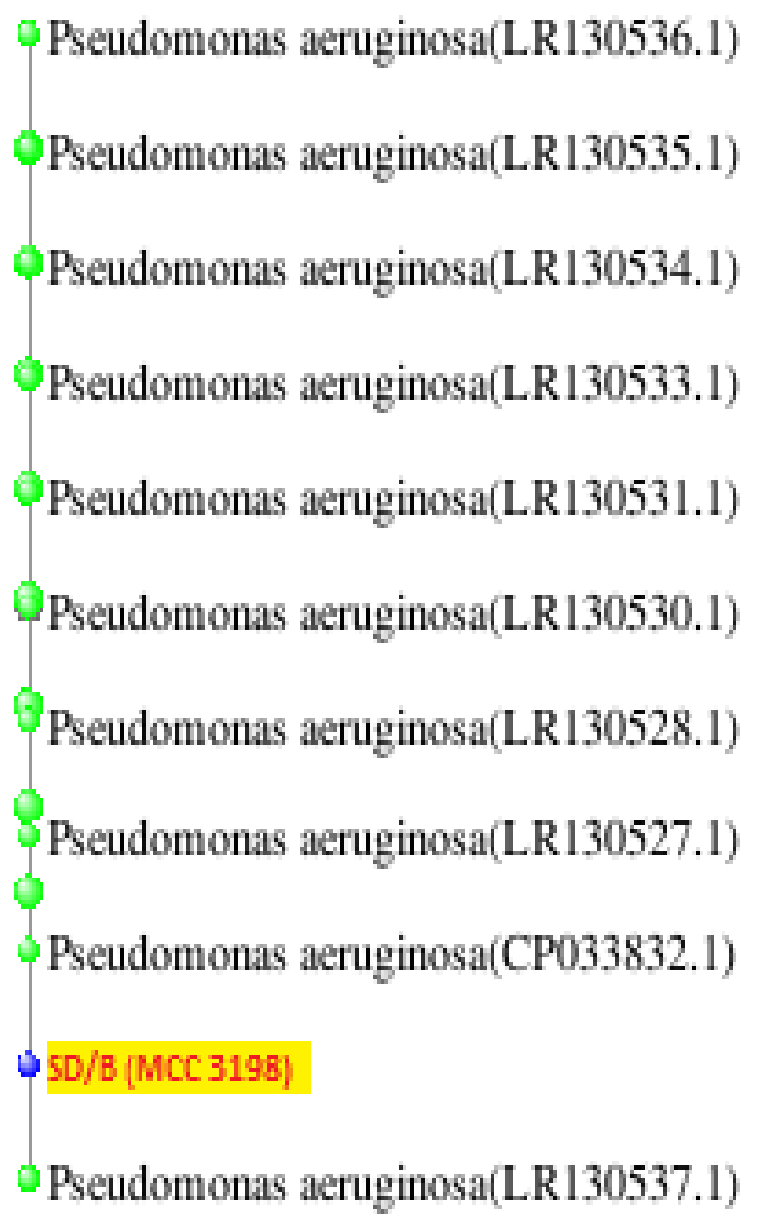


Fig.3 Plate(a) phosphate solublization; (b)- IAA qualitative assay; (c) - IAA quantitative assay; (d)- Ammonia productivity; (e)- Siderophore productivity; (f)- HCN productivity (g) - Control set of seed germination; (h) - PGPR treated set of seed germination; (i) - POX activity of seedling; (j) - Prolin content of treated seedling; (k) - Total chlorophyll of seedling;(l) - SOD activity of seedling; (m) - Peroxidase activity of seedling

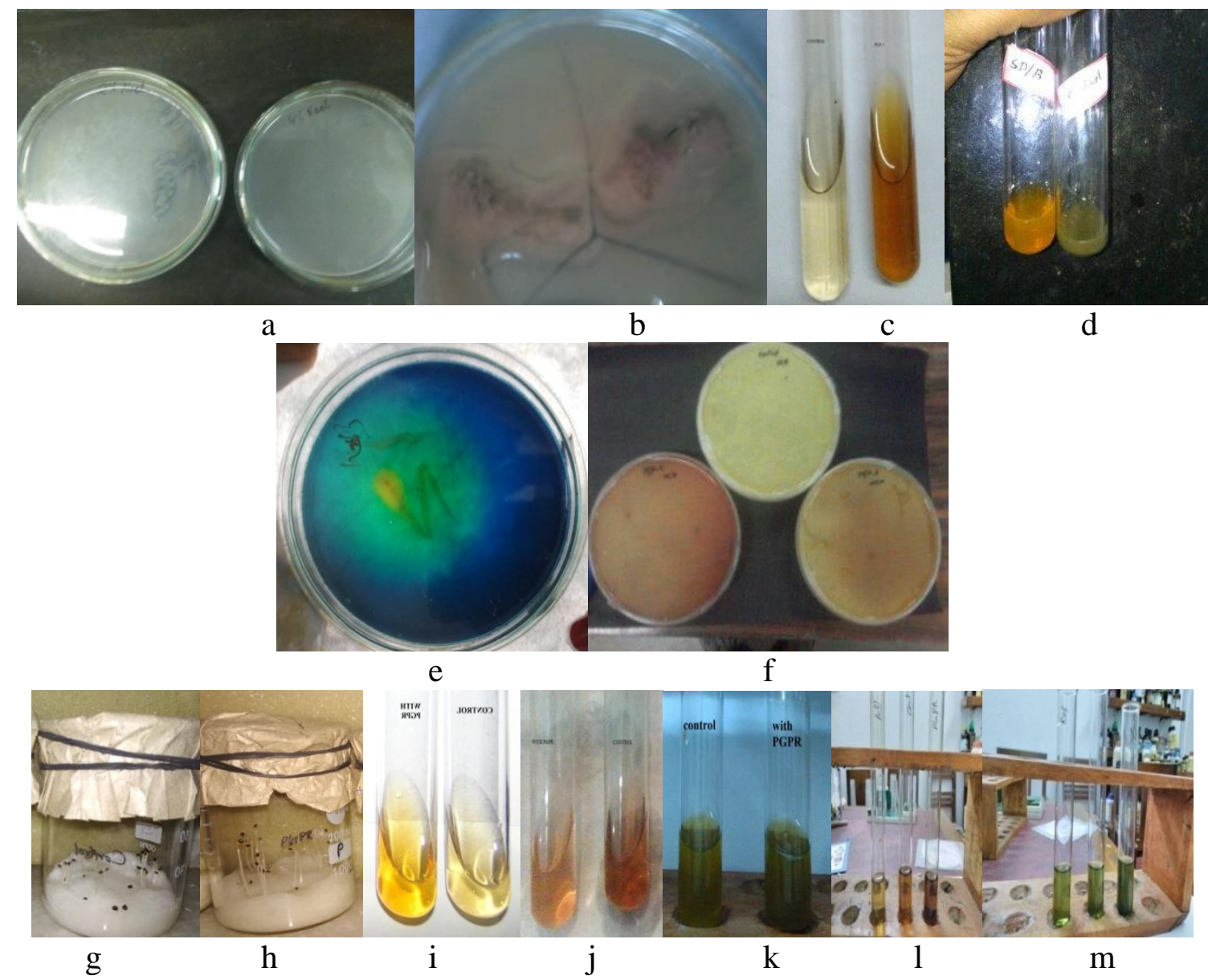

The isolate SD/B exhibited some important PGP traits viz. phosphate solublization ability, atmospheric $\mathrm{N}_{2}$ fixing ability as well as IAA productivity, HCN production, ammonia production ability and protease activity in laboratory condition, which were the main criteria of a rhizobacteria to be designated as PGPR (Majeed et al., 2015). These characteristics are considered as important plant growth promoting traits and have been found certainly useful in improving the growth and nitrogen contents of the tested plants by direct mechanism. As this strain was found to fix atmospheric nitrogen, produce indole-3-acetic acid (IAA), siderophores and solubilize inorganic phosphate and $\mathrm{HCN}$ that are capable of stimulating plant growth and help plants to acquire sufficient iron, phosphate, and other essential nutrients for optimum growth (Glick, 1995; Chabot et al., 1996; Rajkumar et al., 2006; Idris et al., 2007).

These important PGP traits found to enhance the plant growth when tested the effect of the bacteria on the seed germination of the ethno medicinal plant $C$. cristata L. Bacterial inoculant was able to increase plant growth 
and germination rate, improve seedling emergence. It exposed that under in vitro conditions, seed treatment with PGPR strains improved seed germination, seedling vigor, seedling emergence, seedling stand, chlorophyll a, b and total chlorophyll content of the PGPR treated seedlings over the control. Comparable enhancement of seed germination parameters by rhizobacteria has been reported in other foliage such as sorghum (Raju et. al., 1999) and Lenin and Jayanthi (2012) showed that a formulation of PGPR including Azospirillum lipoferum, Azotobacter chroococcum, Pseudomonas fluorescens and Bacillus megaterium significantly enhanced germination rate, vigour index and chlorophyll content of medicinal plant Catharanthus roseus.

Besides, this strain also found to enhance the defense related enzymes like superoxide dismutase, peroxidase, ascorbate oxidase, etc. of the treated plant. Which got support from the works of Gururani et al., (2012) and Kohler et al., (2010) PGPR enhances ROSscavenging enzymes such as catalase and ascorbate peroxidase which may help the plants under salinity and drought pressure to stebilize the damaging effects of ROS. Similarly, Ramamoorthy et al., (2002) and Dutta et al., (2008) showed that, the treatment of pathogen-challenged tomato, hot pepper and pigeon pea with luminous Pseudomonads increased activities of POX and PPO. Similarly, Attia and Saad (2001) have showed that vegetative expansion and chemical concerto in medicinal plant Catharanthus roseus were promoted by the mutual management of Azotobacter and phosphatesolubilizing bacteria.

\section{References}

Addy, S.K., and Goodman, S.K. 1972. Polyphenol oxidase and peroxidase activity in apple leaves inoculated with a virulent or an avirulent strain of Erwinia amylovora. Indian phytopath. 25: 575-579.

Aebi, H. 1984. Catalase. In: Packer, L. ed. Methods in enzymol. Academic press, Orlando., 105: 121-126.

Arnon, D.I. 1949. Copper enzymes in isolated chloroplasts. Polyphenoloxidase in Beta vulgaris. Plant Physiol. 24: 1-15.

Attia, F.A., Saad, O.A.O. 2001. Biofertilizers as partial alternative of chemical fertilizer for Catharanthus roseus G. Don. J Agric Sci 26:7208-7193.

Bates, L., Waldren R.P., Teare I.D. 1973. Rapid determination of free proline for water-stress studies. Plant and Soil. 39, 205-207.

Beauchamp C.O., Fridovich I. 1973. Isozymes of superoxide dismutase from wheat germ. Biochem. Biophys. Acta. 317: 50-64.

Benson, J. A., A. E. Flores, C. J. Baker, S. L. Hillier, and P. Ferrieri. 2002. Improved methods for typing nontypeable isolates of group B streptococci. Int. J. Med. Microbiol. 292:37-42.

Brick, J.M., Bostock, R.M., and Silverstone, S.E. 1991. Rapid in situ assay for indole acetic acid production by bacteria immobilized on nitrocellulose membrane. Appl Environ Microbiol. 57:535-538.

Cappuccino, J.C., Sherman, N.. 1992. Microbiology: A Laboratory Manual (third ed), Benjamin/cummings Pub. Co., New York, pp. 125-179.

Chabot, R., Antoun, H., Cescas, M.P. 1996. Growth promotion of maize and lettuce by phosphate solubilizing Rhizobium leguminosarum biovar phaseoli. Plant Soil. 184:311-321

Chaiharn, M., Chunhaleuchanon, S., Kozo, A., Lumyong, S. 2008. Screening of rhizobacteria for their plant growth 
promoting activities. Sci Tech J. 8:1823.

Dutta, S., Mishra, A.K., Dileep Kumar B.S. 2008. Induction of systemic resistance against fusarial wilt in pigeon pea through interaction of plant growth promoting rhizobacteria and rhizobia. Soil Biol Biochem. 40:452-461.

Glick, B.R. 1995. The enhancement of plant growth by free living bacteria. Can $J$ Microbiol. 41: 109-114.

Glick, B.R., Patten, C.L., Penrose, D.M. 1999. Biochemical and genetic mechanisms used by plant growthpromoting bacteria, 1st edn. Imperial College Press, London

Gururani, M.A., Upadhyaya, C.P., Baskar, V., Venkatesh, J., Nookaraju, A., Park, S.W. 2012. Plant growth promoting rhizobacteria enhance abiotic stress tolerance in Solanum tuberosum through inducing changes in the expression of ROS-Scavenging enzymes and improved photosynthetic performance. J Plant Growth Regul. $32: 245-258$.

Idris, S.E., Iglesias, D.J., Talon, M., Borriss, R. 2007. Tryptophan dependent production of Indole-3- Acetic Acid (IAA) affects level of plant growth promotion by Bacillus amyloliquefaciens. Mol Plant Microbe Interact. 20:619-626.

Kohler, J., Caravaca, F., Rolda'n, A. 2010. An AM fungus and a PGPR intensify the adverse effects of salinity on the stability of rhizosphere soil aggregates of Lactuca sativa. Soil Biol Biochem. 42:429-434.

Kumar, S., Stecher, G., Tamura, K. 2016. MEGA7: Molecular Evolutionary Genetics Analysis Version 7.0 for Bigger Datasets. Mol Biol Evol. 33(7):1870-4. doi: 10.1093/molbev/ msw054.
Lenin, G., Jayanthi, M. 2012. Efficiency of plant growth promoting rhizobacteria (PGPR) on enhancement of growth, yield and nutrient content of Catharanthus roseus. Int J Res Pure Appl Microbiol. 2:37-42.

Lorck, H. 1948. Production of hydrocyanic acid by bacteria. Physiol. Plant. 1: 142-146.

Lugtenberg, B., Kamilova, F. 2009. Plant growth-promoting rhizobacteria. Аnпи Rev Microbiol. 63: 541-556.

Majeed, A., Abbasi, M.K., Hameed, S., Imran, A., Rahim, N. 2015 Isolation and characterization of plant growthpromoting rhizobacteria from wheat rhizosphere and their effect on plant growth promotion. Frontiers in Microbiology. 6:198. doi:10.3389/ fmicb.2015.00198.

Mayak, S., Tsipora, T., Bernard, R., Glick, B.R. 2004. Plant growth-promoting bacteria that confer resistance to water stress in tomatoes and peppers. Plant Sci. 166:525-530.

Migula, W. 1900. System der Bakterien, vol 2 Gustav Fischer, Jena, Germany.

Mishra, M., Kumar, U., Mishra, P.K., Prakash, V. 2010. Efficiency of plant growth promoting rhizobacteria for the enhancement of Cicer arietinum $\mathrm{L}$. growth and germination under salinity. Adv Biol Res. 4:92-96.

Pikovskaya, R.I. 1948. Mobilization of Phosphorus in Soil Connection with the Vital Activity of Some Microbial Species. Microbiology. 17: 362-370.

Rajkumar, M., Nagendran, R., Lee, K.J., Lee, W.H., Kim, S.Z. 2006. Influence of plant growth promoting bacteria and $\mathrm{Cr}$ (vi) on the growth of Indian mustard. Chemosphere. 62:741-748.

Raju, N.S., Niranjana, S.R., Janardhana, G.R., Prakash, H.S., Shetty, H.S., and Mathur, S.B. 1999. Improvement of seed quality and field emergence of 
Fusarium moniliforme infected sorghum seeds using biological agents. J. Sci. Food. Agric. 79:206212.

Ramamoorthy, V., Raguchander, T., Samiyappan, R. 2002. Enhancing resistance of tomato and hot pepper to Pythium diseases by seed treatment with fluorescent Pseudomonads. Eur J Plant Pathol. 108:429-441.

Ramamoorthy, V., Viswanathan, R., Raguchander, T., Prakasam, V., Samiyappan, R. 2001. Induction of systemic resistance by plant growth promoting rhizobacteria in crop plants against pest and diseases. Crop Prot. 20:1-11.

Sambrook, J., Fritschi, E.F. and Maniatis, T. 1989. Molecular cloning: a laboratory manual, Cold Spring Harbor Laboratory Press, New York

Schroeter, J. 1872. Über einige durch Bacterien gebildete Pigmente, p 109-
126. In Cohan F, editor. (ed), Beitrage zur Biologie der Pflanzen. J. U. Kern's Verlag, Breslau, Berlin, Germany.

Schwyn, B., Neilands, J.B. 1987. Universal chemical assay for the detection and determination of siderophores. Anal Biochem. 60(1):47-56.

Vessey, J.K. 2003. Plant growth promoting rhizobacteria as biofertilizers. Plant Soil. 255:571-586.

Vines, H.M. and Oberbacher, M.F. 1965. Response of oxidation and phosphorylation in citrus mitochondria to arsenate. Nature. 206:319-320.

Yoon, S.J., Choi, Y.J., Min, K., Cho, K.K., Kim, J.W., Lee, S.C., et al., 1996. Isolation and identification of phytase producing bacterium, Enterobacter sp. 4 and enzymatic properties of phytase enzyme. Enzym Microb Technol. 18:449-454.

\section{How to cite this article:}

Sunanda Dutta, Avishek Sarkar and Sikha Dutta. 2019. Characterization of Pseudomonas aeruginosa MCC 3198 and its Potential for Growth Promotion of Seedlings of the Medicinal Plant Celosia cristata L. Int.J.Curr.Microbiol.App.Sci. 8(04): 985-997. doi: https://doi.org/10.20546/ijcmas.2019.804.114 